\title{
The nanophthalmic macula
}

\author{
J C Serrano, P R Hodgkins, D S I Taylor, G A Gole, A Kriss
}

\begin{abstract}
Aims-To define an unusual macular appearance found in association with nanophthalmos.

Methods-A case review.

Results-Seven children (aged 8 months to 17 years) with nanophthalmos were examined. They all exhibited the same clinical findings of an unusual yellow macula appearance with retinal folds and crowded optic discs. Visual electrophysiology performed in four cases was normal.

Conclusion-A distinctive yellow macular pigmentation with associated chorioretinal folds and crowded optic discs is present in nanophthalmos. It is proposed that the retinal folds are due to a disparity between scleral and retinal growth while the macula discoloration is due to a congenital abnormality in arrangement or position of the luteal pigment and is not degenerative. Included in this case series is the second case in the literature of nanophthalmos associated with Kenny's syndrome. Inheritance of nanophthalmos appears to be autosomal recessive. (Br f Ophthalmol 1998;82:276-279)
\end{abstract}

Nanophthalmos is a rare condition consequent upon arrest in the development of the globe in all dimensions. This occurs after the fetal fissure has closed ${ }^{1}$ and without other major malformations. ${ }^{23}$ Nanophthalmos has sometimes been considered within the spectrum of microphthalmos rather than as a distinct condition $^{45}$ despite it exhibiting well defined morphological and clinical characteristics to separate it. $^{246-10}$ Typically, microphthalmic eyes have other structural changes and are frequently associated with systemic abnormalities, whereas in nanophthalmos other ocular or systemic anomalies are generally absent al-

Ophthalmology, Great Ormond Street

Hospital for Children, Great Ormond Street, London WC1N 3JH

J C Serrano

P R Hodgkins

D S I Taylor

A Kriss

Department Of

Ophthalmology, Royal

Children's Hospital,

Brisbane, Queensland,

Australia

G A Gole

Correspondence to: Mr D Taylor.

Accepted for publication 29 September 1997

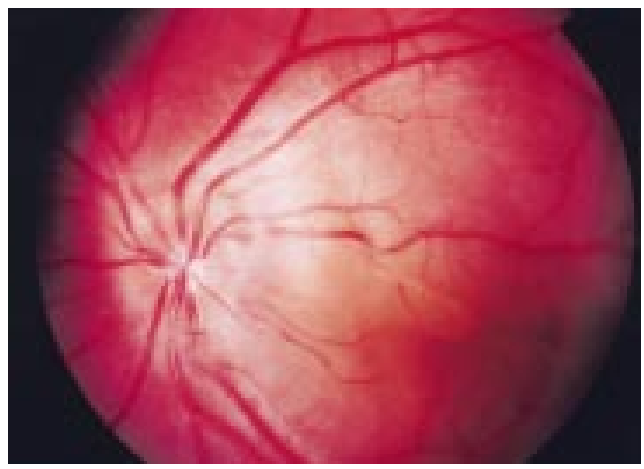

Figure 1 Fundus photograph of case 1 with a retinal pigment epithelial disturbance evident along with a yellow appearance at macula, retinal folds, and crowded optic discs. though there are reports of associations with: cryptorchidism, ${ }^{11}$ Kenny's syndrome, ${ }^{12}$ Hallerman-Streiff-Francois syndrome, ${ }^{13}$ and oculodentodigital syndrome. ${ }^{14} 15$

Different funduscopic appearances associated with nanophthalmos have been described including macular hypoplasia ${ }^{4}$; retinal cysts and pseudopapilloedema ${ }^{46}{ }^{16}$; pigmentary retinal dystrophy with optic disc pallor and vascular narrowing ${ }^{6}$; macular cysts ${ }^{6}$; and horizontal retinal macular striae in association with geographic areas of pigmentary retinal epithelium disturbance and choroidal thickening. ${ }^{2}$

We describe seven cases of nanophthalmos with an unusual macular appearance, one of which appears to be associated with Kenny's syndrome, and we discuss the mode of inheritance.

Materials and methods

In all seven cases there was extreme hypermetropia, small corneas, shallow anterior chambers, but normal lens size. Fundal examination revealed chorioretinal folds with an unusual appearance at the macula with optic disc crowding (Figs 1-5). For a summary of the findings see Table 1 .

In case 6 a genetics referral was made because he was also noted to be of short stature with unusual facies (Fig 6) although he had a normal intellectual level of development. Radiological investigation revealed thickened long bone cortex with stenotic medullary cavities and, although transient hypocalcaemia could not be proved, a presumptive diagnosis of Kenny's syndrome was made.

\section{Results}

Seven children aged 8 months to 17 years, with findings consistent with nanophthalmos were examined. All were phakic with excessive hypermetropia (+13.25 to +17.25 DS) without other ophthalmic malformations. They all exhibited the same clinical findings of an
Figure 2 Fundus photograph of case 1 with a retinal pigment epithelial disturbance evident along with a yellow appearance at macula, retinal folds, and crowded optic discs. 


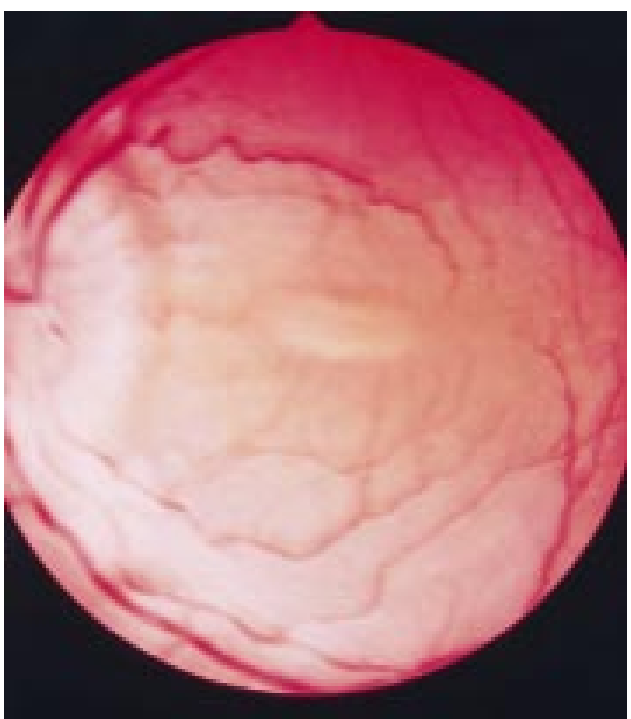

Figure 3 This shows the prominent yellow appearance at the macula with a tag appearance centrally, retinal folds and crowded optic discs.

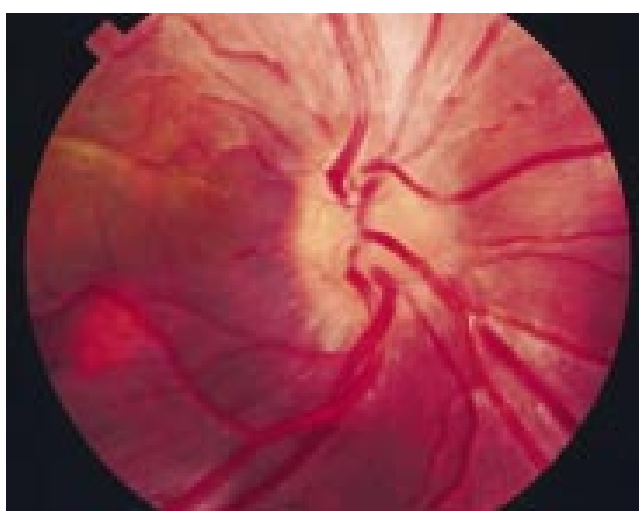

Figure 4 Fundal photograph showing a generalised retinal pigment epithelial disturbance, a prominent yellow macula appearance, retinal folds, and crowded optic discs.

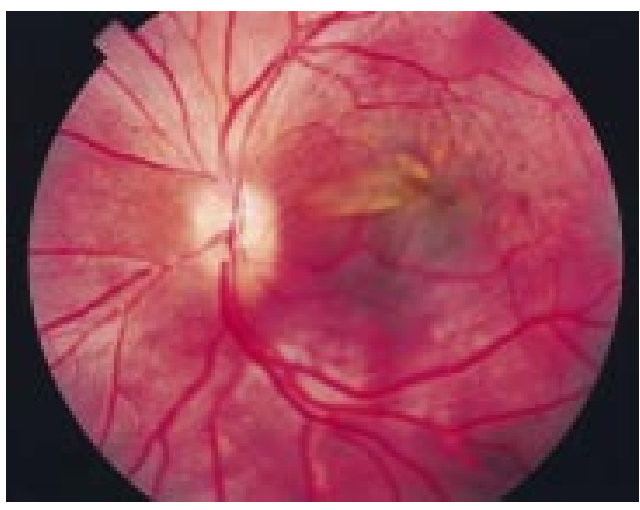

Figure 5 Fundal photograph showing a generalised retinal pigment epithelial disturbance, a prominent yellow macula appearance, retinal folds, and crowded optic discs.

unusual yellow macula appearance with retinal folds and crowded optic discs. One case had unusual facies and radiological examination revealed thickened long bone cortex consistent with a diagnosis of Kenny's syndrome.

Visual electrophysiology was available on four patients with the flash electroretinogram (ERG) within normal amplitude limits although $10 \%$ less than the laboratory average. Similarly, pattern visual evoked potential

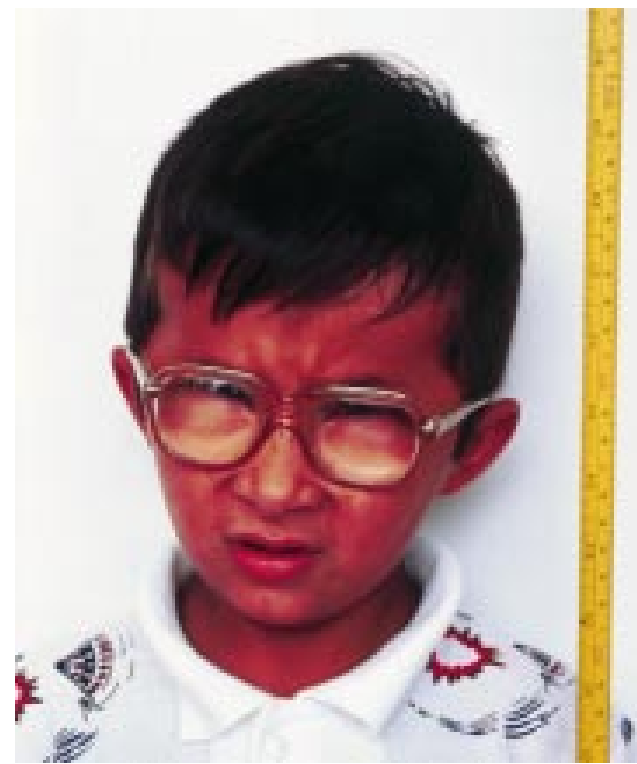

Figure 6 Presumed Kenny's syndrome with atypical facial appearance, short stature, prominent forehead, and micrognathia as well as nanophthalmia.

(VEP) was within normal latency and amplitude limits though binocular amplitude was an average $20 \%$ smaller than the laboratory average. Fluorescein angiograms were not available.

\section{Discussion}

Nanophthalmic eyes are typically deep set, associated with narrow palpebral fissures, ${ }^{37} 17$ and are markedly hypermetropic ${ }^{246-810}$ with axial lengths less than $20 \mathrm{~mm} .{ }^{9}$ They have thickened sclera, small corneal diameters, ${ }^{17}$ and general crowding of the anterior chamber with normal sized lenses, making them prone to angle closure glaucoma. ${ }^{467101819}$ Although hypermetropia is the rule, emmetropia ${ }^{20}$ or myopia $^{41019}$ occurs by corneal or lenticular compensation for the short axial length. Other values that have been proposed as diagnostic variables of this condition include ocular volume reduced to two thirds of normal ${ }^{4}$; reduction in ocular size by $15 \%,{ }^{19}$ and ultrasonic measurements of axial length $2 \mathrm{SD}$ below the mean which is usually considered as $20 \mathrm{~mm}$ or less. ${ }^{1821}$ Ultrasound studies are important, firstly, to look for thickened sclera but also to exclude other ocular abnormalities. It is also helpful in confirming whether the reduction in size is confined to one segment as in anterior or posterior microphthalmos. ${ }^{162022} 23$

A characteristic of nanophthalmos is that the sclera and cornea appear too small compared with the intraocular contents. Abnormal deposits of glycosaminoglycans ${ }^{24}{ }^{25}$ and elevated levels of fibronectin, ${ }^{26}$ which is involved in cellular adhesion, ${ }^{27}$ may contribute to the irregular arrangement of collagen bundles found in the sclera of nanophthalmic eyes..$^{28}$ This abnormal sclera probably then fails to grow normally. ${ }^{13}$ Accumulation of these abnormal products may also thicken the sclera and provide a hydrophilic surface, causing obstruction of the suprachoroidal drainage pathway. ${ }^{132-31}$ This leads to choroidal 
Table 1 Summary of general ocular findings

\begin{tabular}{|c|c|c|c|c|c|c|c|c|}
\hline & Age seen & Cycloplegic refraction & $V A$ & Colour vision & Axial length (mm) & $\begin{array}{l}\text { Lens scleral } \\
\text { ultrasound }\end{array}$ & $V E P$ & $E R G$ \\
\hline 1 & 7 years & $\begin{array}{l}\mathrm{R}+16.00 \mathrm{DS} \\
\mathrm{L}+14.5 / 0.75 \mathrm{DC}\end{array}$ & $\begin{array}{l}\text { R } 6 / 24 \\
\text { L } 6 / 24\end{array}$ & normal & $\begin{array}{l}\text { R } 15.9 \\
\text { L } 15.3\end{array}$ & $\begin{array}{l}\text { Lens } 4.4 \mathrm{~mm} \text {, } \\
\text { Sclera } 2 \mathrm{~mm} \mathrm{R}+\mathrm{L}\end{array}$ & $\begin{array}{l}\text { Pattern VEP of normal } \\
\text { latency though } \\
\text { marginally smaller } \\
\text { than average }\end{array}$ & $\begin{array}{l}\text { Normal mixed } \\
\text { rod/cone response }\end{array}$ \\
\hline 2 & 5 years & $\begin{array}{l}\mathrm{R}+14.5 \mathrm{DS} \\
\mathrm{L}+13.25 \mathrm{DS}\end{array}$ & $\begin{array}{l}\text { R } 6 / 18 \\
\text { L 6/18 }\end{array}$ & normal & $\begin{array}{l}\text { R } 15.2 \\
\text { L } 15.5\end{array}$ & $\begin{array}{l}\text { Lens } 4.2 \mathrm{~mm} \text {, } \\
\text { Sclera } 1.4 \mathrm{~mm} \\
\mathrm{R}+\mathrm{L}\end{array}$ & $\begin{array}{l}\text { Pattern VEP normal } \\
\text { latency slightly small } \\
\text { amplitude }\end{array}$ & $\begin{array}{l}\text { Normal mixed } \\
\text { rod/cone response }\end{array}$ \\
\hline 3 & 3 years & $\begin{array}{l}\mathrm{R}+16.0 \mathrm{DS} \\
\mathrm{L}+16 \mathrm{DS} / 0.5 \mathrm{DC}\end{array}$ & $\begin{array}{l}\text { R 6/18 } \\
\text { L 6/18 }\end{array}$ & normal & NA & NA & $\begin{array}{l}\text { Pattern VEP of normal } \\
\text { latency, marginally } \\
\text { smaller than average }\end{array}$ & $\begin{array}{l}\text { Normal mixed } \\
\text { rod/cone response. }\end{array}$ \\
\hline 4 & 8 months & $\begin{array}{l}\mathrm{R}+17 \mathrm{DS} \\
\mathrm{L}+15.5 \mathrm{DS}\end{array}$ & $\begin{array}{l}\text { CSM } \\
\text { CSM }\end{array}$ & NA & NA & NA & $\begin{array}{l}\text { Pattern VEP of normal } \\
\text { latency, amplitudes } \\
\text { less than lab average }\end{array}$ & $\begin{array}{l}\text { Normal mixed } \\
\text { rod/cone response }\end{array}$ \\
\hline 5 & 5 years & $\begin{array}{l}\mathrm{R}+16.25 \mathrm{DS} \\
\mathrm{L}+17.0 / 1.5 \mathrm{DC}\end{array}$ & $\begin{array}{l}\text { R } 6 / 36 \\
\text { L } 6 / 24\end{array}$ & normal & $\begin{array}{l}\text { R } 15.2 \\
\text { L } 15.4\end{array}$ & $\begin{array}{l}\text { Sclera } 2.1 \mathrm{~mm} \\
\mathrm{R}+\mathrm{L}\end{array}$ & NA & NA \\
\hline 6 & 8 years & $\begin{array}{l}\mathrm{R}+14.5 \mathrm{DS} \\
\mathrm{L}+14.5 \mathrm{DS}\end{array}$ & $\begin{array}{l}\text { R } 6 / 60 \\
\text { L } 6 / 36\end{array}$ & NA & $\begin{array}{l}\mathrm{R} 12 \\
\mathrm{~L} 12\end{array}$ & $\begin{array}{l}\text { Sclera } 2.2 \mathrm{~mm} \\
\mathrm{R}+\mathrm{L}\end{array}$ & NA & NA \\
\hline 7 & 3 years & $\begin{array}{l}\mathrm{R}+17.0 \mathrm{DS} \\
\mathrm{L}+17.0 \mathrm{DS}\end{array}$ & $\begin{array}{l}\text { R } 6 / 60 \\
\text { L } 6 / 60\end{array}$ & NA & NA & NA & NA & NA \\
\hline
\end{tabular}

In all cases the intraocular pressure was normal. All cases also exhibited anterior segments with small corneas and shallow anterior chambers but normal appearing lens size giving rise to a very crowded appearance.

congestion, which can damage the retinal pigmentary epithelial pump causing accumulation of fluid and subsequent choroidal and retinal non-rhegmatogenous detachment, ${ }^{32} 33$ either insidiously or acutely after intraocular surgery. The abnormal growth of the sclera does not affect the lens, which obtains normal volume leading to a high lens/intraocular volume ratio. A similar disparity in growth between the sclera and retina probably gives rise to the retinal folds as seen in our patients and reported by others. ${ }^{21} 22$

The high refractive errors leading to ametropic amblyopia, associated strabismus leading to strabismic amblyopia, and macular changes are the leading causes of reduced vision in childhood nanophthalmos. In contrast, the leading causes of visual loss in adults with nanophthalmos are glaucoma and the high rate of complications following intraocular surgery. ${ }^{89}$ It is recommended that all conservative therapeutic measures should be tried before intraocular surgery ${ }^{894}$ in cases of nanophthalmos.

We present seven patients with a clinical diagnosis of nanophthalmos, two pairs of sisters and three isolated cases, who have all shown a distinctive ophthalmoscopic appearance of the fundi. The clinical features suggesting nanophthalmos in these patients were the deep set eyes with small palpebral fissures, microcornea, very high hypermetropia associated with esotropia (cases 1, 2, 3, and 5), narrow anterior chambers and short axial length of both eyes below $20 \mathrm{~mm}$. Fundal examination revealed crowded optic discs with papillomacular folds and a macula with a distinctive yellow appearance. The increased yellowing may correspond to: (1) an increased density of yellow foveal pigment (xanthophyll) in the inner and outer plexiform layers due to compaction or crowding; (2) an optical phenomenon or early phase of retinal luteal pigmentary disturbance due to an absence of retinal pigment epithelium with abnormal choriocapillaris $^{16}$; (3) an atypical or abnormal xanthophyll being formed. Retinal changes associated with the fundal appearance are likely to alter the function of the photoreceptors affecting the visual acuity, although function was preserved sufficiently to allow normal colour vision. The presence of the same macula appearance in an 8 month old child (case 4) suggests this is not an involutional process but in fact a congenital abnormality associated with nanophthalmos. However, the functional changes associated with nanophthalmos appear subtle. The visual electrophysiology results in four of our cases did not show significant abnormalities. The mixed cone/rod ERG was clearly normal in all cases tested, though there were marginal nonsignificant changes in the amplitude of both the pattern ERG and, more conspicuously, in the pattern VEP. These findings indicate subtle macular pathway dysfunction, though they do not distinguish between the possible effects due to unusual macular anatomy from those associated with ametropic amblyopia due to extreme congenital hypermetropia.

The majority of cases of nanophthalmos reported in the literature are sporadic, but some pedigrees of affected patients have suggested autosomal recessive inheritance 2671735 and occasionally autosomal dominant. ${ }^{46}$ The cases in this series suggest an autosomal recessive trait on the grounds that two family members were affected in the same sibship with normal parents in two separate families. Although no consanguinity can be established in cases 3 and 4 it is probable the parents were related as they were from a small isolated community.

In 1966, Kenny ${ }^{37}$ described two patients with a congenital syndrome comprising of dwarfism, thickened long bone cortex, transient hypocalcaemia, and normal intelligence. These and other patients were initially incorrectly reported as myopic whereas they were in fact very hypermetropic. A further report ${ }^{12}$ has indicated Kenny's syndrome in association with nanophthalmos. In one of our patients there was felt to be unusual facies and radiological investigation confirmed thickened long bone cortex, although transient hypocalcaemia could not be demonstrated. The 
geneticists still felt this was characteristic of Kenny's syndrome. It is important to be aware of this syndrome as the diagnosis may not be suspected and the patient can undergo dangerous electrolyte disturbances, although this was not present in our patient.

1 Mann I. Developmental abnormalities of the eye. 2 nd ed. Philadelphia: JB Lippincott, 1957.

2 Ryan EA, Zwaan J, Chylack LT Jr. Nanophthalmos with uveal effusion. Clinical and embryologic considerations. Ophthalmology 1982;89:1013-17.

3 Warburg M. Classification of microphthalmos and coloboma. F Med Genet 1993;30:664-9.

4 Duke-Elder S. Anomalies in the size of the eye. In: System of ophthalmology. St Louis: CV Mosby, 1963; 3(pt 2):488-95. Warburg M. Genetics of microphthalmos. Int Ophthalmol 1981;4:45-65.

6 MacKay CJ, Shek MS, Carr RE, et al. Retinal degeneration with nanophthalmos, cystic macular degeneration and with nanophthalmos, cystic macular degeneration and angle closure glaucoma. A new

7 Ghose S, Sachdev MS, Kumar H. Bilateral nanophthalmos, pigmentary retinal dystrophy and angle closure pigmentary retinal dystrophy and angle closure
glaucoma-a new syndrome? Br f Ophthalmol 1985;69: glauco $624-8$.

8 Calhoun FP. The management of glaucoma in nanophthalmos. Trans Am Ophthalmol Soc 1975;73:97-122.

9 Singh OS, Simmons RJ, Brockhurst RJ, et al. Nanophthalmos: a perspective on identification and therapy. Ophthalmology 1982;89:1006-12.

10 Jin JC, Anderson DR. Lasered and unsutured sclerotomy in nanophthalmos. Am f Ophthalmol 1990;109:575-80.

11 Barad RF, Nelson LB, Cowchock FS, et al. Nanophthalmos associated with cryptorchidism. Ann Ophthalmol 1985;17: 284-8.

12 Boynton J, Pheasant T, Johnson B, et al. Ocular findings in Kenny's syndrome. Arch Ophthalmol 1979;97:896-900.

13 Stewart DH, Steeten BW, Brockhurst RJ, et al. Abnormal scleral collagen in nanophthalmos. An ultrastructural scleral collagen in nanophthalmos. An
study. Arch Ophthalmol 1991;109:1017-25.

14 Sugar HS. Oculodentodigital dysplasia with angle closure glaucoma. Am f Ophthalmol 1978;86:36.

15 Patton MA, Laurence KM. Three new cases of oculodentodigital syndrome: development of the facial phenotype. $f$ Med Genet 1985;222:386.

16 Fried M, Meyer-Schwickerath G, Koch A. Excessive hypermetropia: review and case report documented by echography. Ann Ophthalmol 1982;14:15-19.
17 Cross HE, Yoder F. Familial nanophthalmos. Am f Ophthalmol 1976;81:300-6.

18 Martorina M. Nanophthalmie familiale. $f$ Fr Ophtalmol 1988;11:357-61.

19 O'Grady RB. Nanophthalmos. Am f Ophthalmol 1971;71: 1251-3.

20 Hirsh SE, Waltman SR, LaPiana FG. Bilateral nanophthalmos. Arch Ophthalmol 1973;89:353.

21 Weiss AH, Kousseff BG, Ross EA, et al. Simple microphthalmos. Arch Ophthalmol 1989;107:1625-30.

22 Spitznas M, Gerke E, Bateman JB. Hereditary posterior microphthalmos with papillomacular fold and high hyperopia. Arch Ophthalmol 1983;101:413-17.

23 Meire F, Leys M, Boghaert S, et al. Posterior microphthalmos. Bull Soc Belge Ophtalmol 1989;231:101-6.

24 Shiono T, Shoji A, Mutoh T, Tamai M. Abnormal sclerocytes in nanophthalmos. Graefes Arch Clin Exp Ophthalmol 1992;230:348-51.

25 Kawamura M, Tajima S, Azuma N, et al. Biochemical studies of glycosaminoglycans in nanophthalmic sclera. Graefes Arch Clin Exp Ophthalmol 1995;233:58-62.

26 Yue BY, Kurosawa A, Duvall J, et al. Nanophthalmic sclera. Fibronectin studies. Ophthalmology 1988;95:56-60.

27 Hynes RO. Fibronectins. Sci Am 1986;254:42-51.

28 Yue BY, Duvall J, Goldberg MF, et al. Nanophthalmic sclera. Morphologic and tissue culture studies. Ophthalmology 1986;93:534-41.

29 Trelstad RL, Silbermann NN, Brockhurst RJ. Nanophthalmic sclera. Ultrastructural, histochemical and biochemical observations. Arch Ophthalmol 1982;100:1935-8.

30 Allen KM, Meyers SM, Zegarra H. Nanophthalmic uveal effusion. Retina 1988;8:145-7.

31 Ward RC, Gragoudas ES, Pon DM, et al. Abnormal scleral findings in uveal effusion syndrome. Am $\mathcal{f}$ Ophthalmol 1988;106:139-46.

32 Gass JD. Uveal effusion syndrome: a new hypothesis concerning pathogenesis and technique of surgical treatment. Trans Am Ophthalmol Soc 1983;81:246-60.

33 Brockhurst RJ. Vortex vein decompression for nanophthalmic uveal effusion. Arch Ophthalmol 1980;98:1987-90.

34 Kimbrough RL, Trempe CS, Brockhurst RJ, et al. Angle closure glaucoma in nanophthalmos. Am f Ophthalmol 1979;88:572-9.

35 Brockhurst RJ. Nanophthalmos with uveal effusion: a new clinical entity. Arch Ophthalmol 1975;93:1289.

36 Vingolo EM, Steindl K, Forte R, et al. Autosomal dominant simple microphthalmos. f Med Genet 1994;31:712-25.

37 Kenny FM, Linarelli L. Dwarfism and cortical thickening of tubular bones. Am F Dis Child 1966;111:201-7. 